\title{
A QUESTÃO SOCIAL E O CONTEXTO AMAZÔNICO
}

\section{The social question and the Amazonian context}

Luiz Felipe Barboza Lacerda
Psicólogo pós-graduado em Psicologia Transpessoal
pela Associação Luso-brasileira de Transpessoal e
Doutor em Ciências Sociais pela UNISINOS.
Secretário Executivo do Observatório Nacional de
Justiça Socioambiental Luciano Mendes de Almeida
- OLMA.
E-mal: olma @jesuitasbrasil.org.br
Marília Veríssimo Veronese
Doutorado em Psicologia Social pela PUC-RS
(2004). Professora da Universidade do Vale do Rio
dos Sinos (UNISINOS).
E-mail: $\begin{array}{r}\text { mariliav@ @nisinos.br } \\ \text { Informações do artigo } \\ \text { Recebido em: } 20 / 12 / 2016 \\ \text { Aceito em: 03/03/2017 }\end{array}$

\begin{abstract}
Resumo
Qual é a atual Questão Social da Amazônia? O artigo busca tal resposta a partir da articulação entre o conceito de questão social em Robert Castel, as especificidades da América Latina e a realidade da região amazônica do Alto Solimões, bem como das políticas públicas concebidas e implementadas para dar conta dos problemas lá vivenciados. Conclui-se que, na questão social do contexto amazônico estudado, encontram-se elementos de mestiçagem, hibridação, relações de poder e formas de viver típicos da região. Define-se, portanto, como uma questão multifacetada, de configuração própria, não podendo ser explicada com base na análise global. Com origens no colonialismo/colonialidade e posteriormente no assistencialismo, a questão social no contexto amazônico historicamente mostra-se vinculada a interesses secundários, de integração comercial de suas riquezas naturais e ocupação populacional de seus espaços de fronteira.

Palavras-chave: Questão social. Contexto

amazônico. Políticas públicas.
\end{abstract}

\section{Introdução}

As análises sobre a atual conjuntura frente aos contextos econômicos nacionais e internacionais são campo de grande complexidade, sendo não raro contraditórias. Quando analisamos os períodos entre 1 de janeiro de 2003 a 31 de agosto de 2016 (portanto antes do golpe de estado que atualmente vigora) encontramos no Brasil maiores taxas de ocupação formal, e políticas de transferência condicionada de renda, desenha-se, globalmente, a fratura de sociedades desenvolvidas sobre a premissa salarial, principalmente no contexto europeu. Através do processo de mundialização do mercado e a minimização da figura do Estado como aparelho regulador, pulverizam-se precariedades por todo o globo.

A máxima da era capitalista industrial, que previa relação harmônica e proporcionalmente evolutiva entre crescimento econômico e desenvolvimento social, termina por promover processos degradantes de exploração e inclusão perversa de grande contingencial humano que, assim, se encontra privado de suas necessidades básicas e de seus direitos fundamentais, gerando um cenário de múltiplas desigualdades sociais.

Este quadro, denominado por Castel (2004) de nova questão social, é colocado em análise ao longo da próxima seção, para posteriormente, através do estudo da realidade 
latino-americana, especificamente do contexto amazônico, demonstrar que, nesse caso, sua gênese está datada de muito antes da crise contemporânea da sociedade salarial. Portanto, o conceito de nova questão social, típico da contemporaneidade, parece não se adequar à realidade específica do Alto Solimões. Mas disso se ocuparão seções posteriores do texto.

Segundo a definição tomada do autor francês, a questão social ganha novos contornos no âmbito da mundialização, multiplicando-se em suas formas de manifestação nos distintos contextos sociais, podendo ser analisada por diferentes aspectos. São justamente esses distintos modos de manifestação da questão social, que em cada contexto apresenta suas idiossincrasias, que nos interessa analisar, primeiramente em termos de mundialização e aspectos relativos ao trabalho e posteriormente a partir do foco na realidade amazônica.

\section{A relação entre trabalho e questão social}

Este preâmbulo objetiva caracterizar a questão social contemporânea e alguns de seus principais aspectos, especialmente sob o marco teórico de Robert Castel (1997). O trabalho tem sido tema central para as análises das dinâmicas sociais desde a instituição da pesquisa social moderna. Já nos escritos dos fundadores das ciências sociais que introduziram seu corpus inaugural (Marx, Weber e Durkheim), percebemos a abordagem do trabalho como fenômeno que implica laços sociais, analisado de diferentes ângulos: Marx via o trabalho ideal como aquele que possibilitaria a realização da essência humana e a libertação do homem, sendo que, para ele, o trabalho no contexto capitalista foi caracterizado como fonte de alienação e exploração. Weber, por sua vez, entendia a ética protestante como forma de valorizar o trabalho e a acumulação, ingredientes essenciais para o desenvolvimento do capitalismo; contudo, também apontava o trabalho como fonte de encerramento do homem numa sociedade dominada pela burocracia. Durkheim, com sua análise estrutural, percebia na divisão social do trabalho os elementos que garantiriam a coesão social, apontando também a desvalorização do trabalho como fenômeno de anomia social. (NARDI, 2006).

Com o advento da revolução industrial e suas reverberações, o trabalho como elemento de coesão social passa a ser questionado a partir de suas próprias contradições. 0 desenvolvimento do capitalismo industrial, atingindo posteriormente escalas globalizadas, explicita que as aspirações de uma sociedade de pleno emprego, desenvolvimento e autossustentabilidade, (instigada pela livre concorrência e não interferência da esfera estatal 
no mercado financeiro) não se realizavam, isso quando não geravam efeito contrário, produzindo desigualdades sociais, bolsões de pobreza e escassez dos recursos naturais.

Mesmo com tais efeitos colaterais, o sistema industrial e com ele o trabalho assalariado, seguiu ganhando espaço e garantindo status social aos diversos atores, especialmente os que ocupavam os empregos e salários socialmente desejados. Méda (2005, p.18) apresenta uma concepção de origem marxiana que reforça a centralidade do trabalho na vida humana, para além das estruturas modernas de assalariamento, afirmando que:

O trabalho é uma atividade essencial do homem, graças ao qual ele é colocado em contato com sua exterioridade, a natureza, a qual ele se opõe para criar as coisas humanas, - é com os outros e para os outros que ele realiza sua tarefa. $O$ trabalho é, portanto, aquilo que exprime de forma mais importante nossa humanidade, nossa condição fim, criador de valor, mas também de nossa auto-criação como seres sociais. $O$ trabalho é nossa essência e também nossa condição.

O marco inicial do ciclo onde o trabalho assalariado cada vez ganhará maior centralidade nas estruturas sociais encontra-se representado na reforma protestante, quando o lucro deixou de ser punido para ser desejado: acumular e conquistar bens materiais passa a ser considerado uma bênção de Deus. Nesse sentido, uma série de pequenos elementos nos desenham os pensamentos da época, como em 1748, quando Benjamin Franklin cria a famosa expressão "tempo é dinheiro", e em 1776, quando Adam Smith publica A riqueza das nações, identificando o trabalho como principal elemento na produção das riquezas. A citação de Medá exposta acima apresenta a confluência das concepções cristãs, marxistas e humanistas a partir das quais o trabalho se torna a essência do homem (NARDI, 2006).

Com o tempo desenha-se cada vez mais a consolidação de uma sociedade salarial. No século XX, as relações de trabalho assumem caráter contratual, transformando-se assim no chamado emprego. O emprego seria a forma primordial de inclusão na sociedade salarial, pois, atrelado a ele, estiveram os direitos sociais e cívicos, e, a partir dele, desenvolveu-se um complexo universo jurídico para estabelecer as relações de direitos e deveres entre empregados e empregadores.

Sobre essa transformação histórica a respeito do trabalho e a consolidação de uma sociedade industrial/salarial, Robert Castel (1997), sociólogo francês, desenvolve vasta obra. O autor descreve a Questão Social, referindo-se a um fenômeno a partir do qual, frente a uma dificuldade central, a sociedade se interroga sobre sua coesão e tenta conjurar o risco de sua fratura. Essa ameaça de fratura é representada historicamente pelo movimento dos 
primeiros proletários, que passam a assumir lugar marginalizado no contexto social e, assim, ameaçam a ordem vigente pelas ações revolucionárias organizadas. Essa situação encontrase como consequência direta da transformação do trabalho em emprego.

O trabalho assalariado, até o processo de industrialização, sempre esteve relacionado a concepções pejorativas, ligado às condições de miséria, pois quem trabalhava era o escravo ou o servo, o camponês curvado sobre suas terras, isto é, pessoas 'de bem' não trabalham, pelo menos não com seus próprios braços. O assalariado, antes de tudo, é aquele que não tem nada, não tem propriedade, aquele que tem apenas a força de seus braços para vender. Era esse o imaginário social a respeito do trabalho assalariado que se apresentava ao longo do século XVIII e no início do século XIX.

De acordo o autor, é na segunda metade do século XIX que ocorre um conjunto de conflitos e lutas que convergem para a ideia de que o salário não é mais uma situação provisória e miserável. Com o desenvolvimento da industrialização e da urbanização, o trabalho se instala e passa a ser um estado permanente e desejável de sobrevivência.

\footnotetext{
Uma sociedade salarial é sobretudo uma sociedade na qual a maioria dos sujeitos sociais tem sua inserção social relacionada ao lugar que ocupam no salário, ou seja, não somente sua renda mas, também, seu status, sua proteção, sua identidade. Poder-se-ia dizer que a sociedade salarial inventou um novo tipo de seguridade ligada ao trabalho, e não somente à propriedade, ao patrimônio. Antes do estabelecimento desta sociedade salarial ser protegido era ter bens; somente quando se era proprietário é que se estava garantido contra os principais perigos da existência social, que são a doença, o acidente, a velhice sem pecúlio. (CASTEL, 1997, p. 243).
}

Dessa forma, o salário se consolidou e se dignificou, possuindo um efeito atrativo em torno do qual a sociedade moderna se organizou. Deu-se o ápice do processo de legitimidade deste novo momento de constituição de uma sociedade salarial quando os próprios proprietários de grandes empresas, representantes da classe burguesa, passaram a colocar seus filhos no mercado assalariado por meio de grandes escolas, cursos, diplomas, etc. Transforma-se, portanto, o salário em algo seguramente rentável, atrelando-o, de maneira hierárquica, a posições de prestígio e poder social.

Como aponta Castel (1997), a sociedade salarial é uma sociedade que permanece fortemente hierarquizada, não é uma sociedade igualitária, reproduz injustiças e explorações e, assim. caracteriza-se como uma sociedade conflituosa, onde diferentes grupos sociais são concorrentes. Essas percepções colocam sob suspeita os ideais das correntes social- 
democratas quando afirmavam que, através do lema do livre progresso financeiro, atingiríamos a diminuição das injustiças e desigualdades sociais.

Dedecca e Baltar (1997) destacam que o crescimento do mercado de trabalho assalariado, apesar de substancial, não consolidou a esperada tendência de homogeneização da estrutura operacional, tanto se tratando das formas de trabalho como dos padrões de remuneração. As dificuldades de conseguir uma inserção produtiva mais estável, com melhores condições de trabalho, amparada por um sistema de proteção social, assim como um nível de remuneração mais elevado, continuaram presentes para a maioria da força de trabalho, tanto no meio rural quanto no meio urbano.

Como aponta Wanderley (2004), inicialmente os problemas gerados pela industrialização e a concentração de mão de obra nos centros urbanos foram considerados como assunto de higiene pública e de controle da ordem social, o que é simbolizado pela célebre frase, atribuída a Washington Luís, de que a questão social é uma questão de polícia. Esta mentalidade trouxe como consequência a criminalização do pobre e do desempregado, posteriormente contribuindo também para a construção da imagem da classe trabalhadora como uma classe perigosa.

Castel (1997) aponta que a sociedade contemporânea vivencia um novo fenômeno que se refere à globalização, ou como prefere denominar o autor, mundialização do mercado, com suas crescentes exigências de concorrência e competitividade. Neste contexto, o senso comum assume a equação que minimiza o preço da força de trabalho e, ao mesmo tempo, maximiza a eficácia produtiva dos grandes complexos empresariais. Assim, desvinculadas de um território específico, as grandes corporações permitem-se migrar pelo globo em busca de maiores incentivos fiscais e menores valores a serem pagos aos trabalhadores. Sem compromisso, inclusive ético, das grandes corporações com os estados nacionais e a sociedade civil, esses conglomerados empresariais passam instigando concorrência, promovendo o uso arbitrário e eventualmente irresponsável dos recursos naturais, além de promoverem o aumento dos índices de desemprego em todo o mundo. Algumas regiões da Amazônia apresentam exemplos ícones destas relações inférteis com as grandes empresas e o mercado mundializado.

Usualmente conceituamos globalização como um fenômeno ao mesmo tempo complexo, ambíguo e ideológico. Entendido como processo de mutação dos mercados financeiros em busca de uma abrangência mundial, não apenas os mercados se globalizam, 
mas também as informações, os valores e múltiplos elementos culturais, criando um sistema de comunicação e troca permanente entre países e continentes.

Obviamente, por si, a globalização não carrega tendências exclusivamente positivas ou negativas, assim como parece óbvio também que o capitalismo, desde sua origem, desenvolveu um processo de internacionalização do capital desigual e combinado, rompendo e integrando fronteiras geográficas com vistas a explorar novos campos e aumentar os lucros. Uma das grandes consequências do processo de mundialização das fronteiras econômicas é a degradação do trabalho e a pauperização de alguns setores produtivos.

Sobre a precarização das formas de trabalho, Castel (1997) aponta o exemplo da França, onde, no momento mais abundante da sociedade salarial na Europa, na década de 1970, os contratos por tempo indeterminado de trabalho eram praticamente hegemônicos, um tipo de contrato que gerava a situação de pleno emprego, ocasionando razoável estabilidade nas condições de renda. Em contrapartida, atualmente, 70\% das novas admissões na França se fazem sob formas ditas atípicas, ou seja, contratos de tempo determinado, interinos, tempo parcial, substitutos e provisórios. Este acontecimento sóciohistórico reverte a lógica da estabilidade para uma situação de instabilidade do emprego como regime dominante.

A precarização do trabalho alimenta o desemprego em última análise, colocando as pessoas em condição de vulnerabilidade. Mas este fenômeno não é homogêneo, toca de diferentes maneiras as diferentes categorias sociais - afeta principalmente os trabalhadores e entre eles os menos qualificados, mas isso não quer dizer que não exista o fantasma do desemprego para os quadros superiores.

Refletindo sobre a condição desse último grupo, Castel (1997) cunhou o termo os desfiliados para referir à desestabilização dos estáveis; trabalhadores que ocupavam uma posição sólida na divisão social de trabalho e que atualmente se encontram cada vez mais ejetados dos circuitos produtivos.

Analisando de maneira conjuntural a sociedade capitalista, percebemos que este universo cada vez maior de desfiliados desenvolve papel fundamental para a funcionalidade do sistema vigente, pois garante a concorrência e assim, a fácil substituição (alta volatilidade) da mão de obra; contribuindo também para seu baixo custo e baixa remuneração. 
Esse sujeito desfiliado é uma das figuras que compõem a nova questão social sugerida por Castel (2004). Uma realidade produzida a partir da desmontagem dos sistemas de proteções e garantias, que, no passado, foram ligados ao emprego.

Uma possível saída para os desfiliados de todas as classes encontra-se na constituição de coletivos fortes, protetores, que resgatam as estruturas de suporte e proteção da pessoa traçando novos horizontes e diluindo suas dificuldades no coletivo, promovendo assim processos de solidariedade coletiva, entre iguais. Dentro dessa lógica, encontramos alguns movimentos de bairro, movimentos sociais mais amplos, inclusive a própria Economia Solidária em sua gênese com os mercados de trocas e a agricultura familiar (Castel, 1997).

\section{É nova ou velha a questão social?}

Alejandra Pastorini (2004), em seu texto intitulado A categoria "questão social" em debate, através da análise dos elementos sociais, econômicos e políticos dos últimos trinta anos, estudando as sociedades capitalistas em seu estágio monopolista, defende a tese de que adjetivar a questão social como nova é subestimar o curso dos processos modernos, que a princípio apresentam novas problemáticas, mas não uma nova problematização.

A ideia de novo em oposição ao antigo presume a superação de alguns elementos fundantes da questão social desenvolvida por Castel, que na análise da autora, não foram superados, mas sim transformados ao longo do tempo.

\footnotetext{
Assim podemos dizer que existem diferentes versões da questão social nos diferentes estágios capitalistas e, portanto, diferentes respostas dadas a ela por parte da sociedade no decorrer da história, mas mantendo os elementos da busca por estabilidade e manutenção da ordem estabelecida, da preocupação da reprodução dos antagonismos e contradições capitalistas e da legitimação social como denominador comum entre as diferentes versões. (PASTORINI, 2004, p. 12).
}

Nesse sentido, a autora deixa clara a ideia de que se a realidade é uma totalidade em movimento, somente uma análise de suas transformações, sem cortes e antagonismos, mas dentro de determinado contexto dialético, pode, de fato, fazer compreender as transformações que se desejam estudar no âmbito desse debate.

Através da análise dessas transformações, a autora evidencia, trazendo a realidade brasileira como exemplo, que pela abertura do mercado interno ao capital estrangeiro e principalmente pelos processos sociais desencadeados pela revolução tecnológica, principalmente na segunda metade do século $X X$, alguns autores passam a pensar na 
superação da velha questão social. Argumenta que, se analisada tal realidade de maneira detalhada, perceberemos que, no centro deste "novo", permanecem as expressões clássicas das contradições presentes nas relações de classes sociais e dessas com o Estado.

Para a autora, a iminência de uma crise filosófica que colocaria em questão a base de sustentação do Estado Providência e com ele a própria concepção de direitos sociais, não é nova, senão uma consequência da precarização da sociedade salarial apontada por Castel (1997), na primeira seção desse texto.

No decorrer de suas análises, Pastorini (2004) critica autores como Rifkin (1997) e Gorz (1987), que assinalam a redução da carga horária de trabalho, o tempo livre criativo e a supervalorização do terceiro setor como metas positivas a serem perseguidas, desenhando certa superação da questão social. Para ela, essas análises não assinalam que o tempo livre na maior parte dos casos é sinônimo de tempo alienado. Nesse sentido, é enfática ao sustentar que o trabalho segue na centralidade da ação e da existência humana, sendo ele a única via de acesso para a emancipação do trabalhador.

Portanto, as principais novidades que se apresentam à questão social original referem-se, de maneira quantitativa, ao trabalho através da diminuição, por exemplo, dos empregos no setor industrial e o aumento no terceiro setor, assim como de maneira qualitativa, nas formas de desenvolver e gerir o trabalho. Tudo isso acompanhado com o aumento dos índices de desemprego e as ligeiras mudanças de perfil das classes economicamente desfavorecidas. Além disso, a ruptura capitalista com o compromisso social, o retrocesso das ações sindicais e o impasse existencial dos partidos políticos de esquerda contribuem para o desenho contemporâneo de um Estado mínimo para o social e máximo para o capital (PASTORINI, 2004).

Claro é, nessa última década, que houve na América Latina alguma resistência a esse modelo de Estado neoliberal. Governos chamados ora de progressistas, ora de populistas, implementaram políticas sociais de transferência de renda e outras de cunho estrutural e subsidiário, voltadas aos mais pobres. Contudo, tais ações não foram suficientes para subverter ou reverter o modelo, pelo menos não no Brasil, onde as elites ainda dominam os rumos da economia e detêm grande parte do poder político. Sobre isso, nos traz Coutinho (2006, p. 107):

Um dos maiores problemas da América do Sul contemporânea é que, desde sua democratização política e liberalização econômica nas últimas décadas do século $X X$, seus governos nacionais vêm sendo eleitos pelas "ruas", com os votos oriundos, 
sobretudo, das populações menos privilegiadas; mas, ainda assim, são forçados a agir em maior sintonia com os "mercados" e com todas as exigências de reformas e ajustes a um mundo cada vez mais globalizado e interdependente que isso implica. Desse modo, caracterizado na região como um estelionato eleitoral em que a expectativa dos eleitores em termos de políticas públicas é deliberadamente frustrada pelos novos governos, o policy switch é consequência, em grande parte, de um processo político contraditório.

Para respeitar a processualidade social, faz-se necessário quebrar o dualismo entre o antes e o agora, o velho e o novo, passado e futuro, buscando no mais atual aquilo que permanece de maneira transformada ao longo do tempo. Sendo assim, deparamo-nos com a premissa de que não há como analisar as questões sociais de cada região ou localidade sob uma fórmula universalizante, como preconiza a teoria econômica social hegemônica e seus macroindicadores.

A transferência de contexto, aqui, faz-se necessária, até porque, na realidade latinoamericana, temos os nunca-filiados, aqueles que jamais estiveram sob o alcance de sistemas de proteção social e que, portanto, não tinham nem mesmo do que se desligarem. Mesmo os governos latino-americanos oriundos da chamada esquerda política têm características muito próprias, fruto de seus respectivos processos históricos. No caso do Brasil, a extensão territorial e as enormes diferenças culturais entre os estados tornam a questão ainda mais multifacetada.

Nesse sentido, assumir a revolução industrial e os processos de precarização do trabalho como único eixo de análise seria deixar de lado peculiaridades fundantes de cada contexto e assim, analisar de maneira parcial as múltiplas manifestações das questões sociais.

Essa teorização sobre a questão social, embora importante para dar-nos uma visão geral da problemática, não se aplica total e indiscriminadamente à realidade latinoamericana. Torna-se necessário realizar uma transferência de contexto, um filtro cultural, para dar conta da diversidade de faces que ela assume, nos diferentes espaços-tempo locais e globais.

\section{Pensando a questão social na América Latina}

Sobre o desenvolvimento da sociedade salarial, analisando o caso específico da América Latina, Wanderley (2004) aponta que a questão social fundante, perpetuada sob formas variáveis nestes últimos 500 anos, centra-se nas desigualdades e injustiças que 
imperam no contexto social dos países deste continente. Ela se funde aos conteúdos e formas assimétricos assumidos pelas relações sociais, em suas múltiplas dimensões econômicas, políticas, culturais e religiosas, polarizando o conjunto das sociedades entre os detentores de certos bens e capitais e os marginalizados, incluídos de maneira perversa.

A década de 1980 é marcante para pensarmos a peculiaridade da questão social nos países latinos, pois, neste período, ocorre a reorganização dos países periféricos sobre os pressupostos neoliberais. A crise da dívida externa, do petróleo e a derrota do socialismo real encontra-se no cerne deste processo de reorganização que coloca os princípios do Banco Mundial e do Fundo Monetário Internacional na centralidade das ações estatais frente às desigualdades sociais. (PASTORINI, 2004).

Em vista disso, tais ações de reestruturação das economias periféricas podem ser compreendidas por três variáveis: "disciplina" orçamentária, estabilização macroeconômica, reformas estruturais de mercado e a retomada dos investimentos para o crescimento econômico.

\begin{abstract}
Desta forma, apoiados na ideia de que as políticas de reestruturação dos países periféricos, em especial os latino-americanos, deveriam ser acompanhadas de reformas culturais, o Banco Mundial, no relatório anula de 1990, indica duas estratégias importantes: a primeira delas é a utilização produtiva do bem de que os pobres mais dispõem: o trabalho, e a segunda refere-se à necessidade de prestação de serviços sociais básicos para os pobres e à igual necessidade de privatizar os serviços destinados aos trabalhadores de melhor renda (MOTA, 1995, p. 79).
\end{abstract}

Seguindo as análises propostas pela autora, encontramos a explícita afirmativa de que não é possível transladar aos países periféricos a discussão da crise do Welfare State e da unilateral influência da revolução tecnológica como forma de explicar as mudanças na questão social. Nesse sentido, a principal diferença entre as sociedades encontra-se, na maioria dos casos, na maneira como foram interligadas as diferentes comunidades nacionais ao mundo capitalista, principalmente no que se refere à absorção da mão de obra, às taxas de crescimento demográfico, às migrações internas, ao tipo de tecnologia incorporada nos processos produtivos e às características do mercado interno (PASTORINI, 2004).

Mas, apesar de influentes, as consequências do falecimento de determinada utopia de sustentabilidade e desenvolvimento social da sociedade salarial não são as únicas responsáveis pela estruturação da questão social latino-americana. Não podemos deixar de levar em conta que pobreza, miséria e exploração são traços históricos constitutivos deste 
continente desde os processos coloniais de exploração predatória, e permanecem na cultura naquilo que Quijano (2005) chama de colonialidade do poder e do saber. Sendo assim, a prerrogativa de Wanderley (2004) em pontuar como fundamental as análises históricas de cada região para o estudo das desigualdades sociais mostram-se imperativas. Sobre a Questão Social na América Latina, o autor afirma que:

\begin{abstract}
Ela se funda nos conteúdos e formas assimétricas assumidos pelas relações sociais, em suas múltiplas dimensões econômicas, políticas, sociais, religiosas, com acento na concentração de poder e de riqueza de classes e setores sociais dominantes e na pobreza generalizada de outras classes de setores sociais que constituem as maiorias populacionais, cujos impactos atingem todas as dimensões da vida social, do cotidiano às determinações estruturais (WANDERLEY, 2004, p. 58).
\end{abstract}

Percebendo que a Questão Social latino-americana se coloca, dentro deste contexto histórico, na imbricação entre Estado, Nação e determinada racionalidade pública; que recai, consequentemente, em estratos populacionais específicos de múltiplas realidades, englobando a questão da mulher, do negro, do quilombola, do camponês, do operário urbano, do índio, dentre outros, podemos afirmar que os problemas constitutivos deste continente não foram superados pelo processo de emancipação do século XIX e de modernização do século XX (WANDERLEY, 2004).

A partir daí, não se pode utilizar a noção de nova questão social de Castel sem relativizar consideravelmente suas características no contexto latino-americano.

Analisando as últimas três décadas dos movimentos econômicos oriundos do processo histórico desigual e concentrador de renda e poder político, Wanderley ilustra:

Se nos anos 1970 o crescimento econômico na América Latina flutuou entre 6\% e $8 \%$, a década de 80 foi considerada perdida, a dívida externa atingiu níveis alarmantes, a inflação era crescente, parecia incontrolável e os países da região (com exceção de Chile, Cuba e Colômbia) tiveram perdas expressivas na renda per capita (2004, p.54).

Frente a essa situação houve a implementação de políticas neoliberais, como os programas especiais de ajustes econômicos, principalmente no início dos anos 1990, monitorados pelo Banco Mundial e Fundo Monetário Internacional. A partir daí, desdobramse cenários variados em contextos distintos. Abordaremos alguns destes casos específicos ao tratarmos do território amazônico na próxima sessão.

Concluímos, embasados nos estudos de Pastorini (2004) e Wanderley (2004), que a questão social latino-americana não é uma consequência natural e direta do processo de desenvolvimento monetário e social do capitalismo moderno, não está principalmente 
fundada na desestruturação da sociedade salarial e nas insuficiências do Estado de Bem-Estar Social e que ela se reveste de peculiaridades que obedecem à lógica de cada território e seus extratos populacionais.

O 'território usado' de Milton Santos (1999), compreendido como uma mediação entre o mundo e a sociedade nacional e local, guarda elementos subjetivos, de percepção, de pertença e de uma rede de materialidades que vêm de muito tempo atrás, a começar pelos processos coloniais, no caso amazônico. Neste sentido, afirmamos que na América Latina, a questão social nem é nova, nem é única.

Por fim, mostra-se evidente que as estratégias na busca de sanar as mazelas que se originam desse quadro histórico tomam a forma de políticas públicas e, em cada território, cada contexto e cada realidade específica, tais políticas apresentam contornos próprios, com motivações ora emancipatórias, ora regulatórias. Nesse sentido, Pastorini (2004, p. 90), afirma:

Por isto, entendermos que as medidas (tanto públicas quanto privadas) que buscam realmente atender as manifestações da questão social na contemporaneidade não podem estar apoiadas na teoria da integração social (como as políticas de inserção ou inclusão), que, em última instância, pretende acomodar os indivíduos à ordem estabelecida. É necessário buscar estratégias que busquem romper com esta ordem, que procurem criar uma contra- hegemonia, mas para isto requer-se ação e sujeitos políticos capazes de romper com a situação de submissão em que vivem.

Wanderley (2004) aproxima-se de Pastorini, ao apontar que para não incorrermos nesse erro seria necessário acima de tudo, através das ações destes sujeitos, democratizar radicalmente o Estado, no sentido de criar outra relação entre este, o mercado e a sociedade civil.

Contextualizados frente à questão social e suas peculiaridades no contexto latinoamericano, a seguir nos debruçamos sobre a realidade amazônica, território de interesse de nosso estudo para, apoiados nas conclusões acima, entendermos como se desenvolve a questão social nesse contexto, suas origens e suas características atuais.

O interesse por tal território surge das próprias vivências do primeiro autor desse artigo que, trabalhando durante os últimos seis anos no acompanhamento de comunidades indígenas e ribeirinhas da região do Alto Solimões, partindo da psicologia social, da sociologia e da economia solidária como prismas de análise, tenta decifrar os códigos que compõem a questão social na relação dessas populações nativas. A região do Alto Solimões 
é conhecida por possuir grande diversidade de recursos biogenéticos de cultivos nativos encontrados na Amazônia brasileira e esse patrimônio tem sido conservado pelos povos indígenas e ribeirinhos. (LACERDA, 2016a).

A região trabalhada compreende nove municípios: Tabatinga, Benjamin Constant, Atalaia do Norte, São Paulo de Olivença, Amaturá, Tonantins, Santo Antônio do Içá, Foz de Jutaí e Fonte Boa, todos fazendo fronteira terrestre ou fluvial com o Peru ou Colômbia. Lançarmos esse olhar analítico para tal realidade, em vistas da questão social, nos parece uma importante oportunidade de compreender os desafios percebidos nas formas de organização e representação dentro das próprias comunidades, assim como frente aos agentes externos, como gestores públicos e privados. Esse fenômeno acaba por gerar problemáticas significativas no tocante à subsistência e melhorias na qualidade de vida de indígenas e ribeirinhos da Amazônia. (LACERDA, 2016a).

\section{Analisando o contexto amazônico}

Os indígenas foram derrotados também pelo assombro. O imperador Montezuma recebeu, em seu palácio as primeiras notícias: um grande "monte" andava mexendo-se pelo mar. Outros mensageiros chegaram depois: "[...] muito espanto Ihe causou ao ouvir, como dispara um canhão, como ressoa seu estrépito, como derruba as pessoas; e atordoam-se os ouvidos. E quando cai o tiro, uma bola de pedra sai de suas entranhas: vai chovendo fogo..." Os estrangeiros traziam "veados" nos quais montavam e "ficavam da altura dos tetos". Por todas as partes tinham o corpo envolto, "somente as caras aparecem. São brancas, como se fossem de cal. Têm cabelo amarelo, embora alguns os tenham pretos. Sua barba é grande..." Montezuma acreditou que era o deus Quetzalcóalt que voltava. Oito presságios haviam anunciado, pouco antes, o retorno. Os caçadores lhe tinham trazido uma ave que tinha na cabeça um diadema redondo com a forma de um espelho, que refletia o céu e o sol em direção do poente. Neste espelho Montezuma viu marchar sobre o México os esquadrões dos guerreiros. O deus Quetzalcóalt tinha vindo pelo leste e pelo leste tinha-se ido: era branco e barbudo. Também branco e barbudo era Viracocha, o deus bissexual dos incas. E o leste era o berço dos antepassados heróicos dos maias (GALEANO, 1999, p. 197).

O Brasil possui cerca de 3,6 milhões de quilômetros quadrados de florestas, ocupando o terceiro lugar entre as nações com maior área florestal depois de Rússia e o Canadá. No mundo neotropical o Brasil possui a maior cobertura florestal. Dos pouco mais de seis milhões de quilômetros quadrados que se estima ter a floresta amazônica na América do Sul, nada menos do que 60\% estão em território brasileiro, segundo as Nações Unidas. Neste território moram aproximadamente 18,1 milhões de pessoas, correspondendo a $11,5 \%$ da população do Brasil (LACERDA, 2016a). 
A região amazônica brasileira está formada por municípios que apresentam populações de até 100 mil habitantes e duas grandes metrópoles com população maior a um milhão de habitantes: Manaus, capital do estado do Amazonas e Belém, capital do Pará, sendo que a população está mais concentrada na porção paraense, oriental e atlântica da Amazônia brasileira. Sendo assim, a Amazônia brasileira tem um adensamento populacional de 3,6 hab/kma refletindo o caráter de "floresta urbanizada" onde cerca de $60 \%$ da população concentra-se nas áreas urbanas ( $15 \mathrm{hab} / \mathrm{km}^{\mathrm{a}}$ ) deixando a área rural para uma ocupação difusa reservada a grupos marginalizados como migrantes nordestinos, indígenas, ribeirinhos e quilombolas. (IBGE, 2010).

Como afirmam Lima; Silva; Sousa (2012), pensar em Amazônia é remeter-se às práticas geopolíticas que permeiam o processo de construção territorial de nosso país. Foi com a incorporação ao domínio do Estado português e sua ampliação territorial que a Amazônia passou a ter prioridade na política da Metrópole. Sendo assim, ao longo de toda a história, evidenciam-se dois objetivos estritos na maioria das intervenções propagadas pelo Estado e outros atores neste contexto: Integração econômica e ocupação territorial.

Tais objetivos, como demonstraremos a seguir, raramente levaram em consideração as contribuições possíveis das (ou para as) populações nativas, geralmente adotando posturas de desconsideração e desrespeito com a preservação e manutenção dos aspectos necessários para a vida com qualidade destas populações, a começar pela total negligência de seus aspectos culturais.

\footnotetext{
A partir da entrada dos colonos e da exploração da mão-de-obra indígena que ocorre a instalação e intensificação da atividade comercial na região. As Drogas do Sertão foram uma das principais atividades comerciais ocorrida pela exploração dos indígenas geridos pelas ordens religiosas (LIMA; SILVA; SOUSA, 2012, p.3).
}

Historicamente, segue tal tendência de exploração tentando aproximar cada vez mais a Amazônia à esfera do capitalismo comercial. Nesse sentido, no contexto colonial, a criação da Companhia do Maranhão e Grão-Pará estabelece uma relação de escala mercantil entre o território e a coroa portuguesa. Contemporaneamente, o estímulo à migração ao norte, com a criação de diversas rodovias e da Zona Franca de Manaus em 1967, representam ações que buscam apenas a concretização atual de uma ordem vigente e preconizante da integração mercantil, do livre fluxo de capitais e da urbanização destacada do aspecto ambiental, muito antiga. 
A visão estrategista dos militares com os governos civis mostra a preocupação em dinamizar a fronteira. Em 1985, é criado no governo José Sarney o Projeto Calha Norte $(P C N)$, a meta do programa era a vigilância da fronteira, a implantação da atividade econômica, o estímulo à migração e aumento da presença do Estado na zona de fronteira. Um novo "ciclo" amazônico começa a ser desenhado com a implantação da Superintendência e Valorização Econômica da Amazônia (SPVEA) em 1953، institucionalizando a Amazônia Legal como área de atuação governamental. Na fomentação de créditos é criado o Banco da Amazônia (BASA) substituindo Banco da Borracha, demonstrando as mudanças de diretrizes econômicas para a região (LIMA; SILVA; SOUSA, 2012, p.5).

De fato, mesmo contando com $3 \%$ das verbas da União, assegurada pela Constituição de 1946, o Banco de Fomento serviu exclusivamente para o financiamento de obras rodoviárias que, posteriormente por incentivo do Estado, implicaram a construção da rodovia Belém -Brasília, realizando a ligação do território amazônico ao planalto central e estimulando a futura pecuária e mineração regional. Nesta fase, geralmente denominada de integrativa, imperava o slogan integrar para não entregar.

Segundo Becker (2005), foi com a formação do moderno aparelho de Estado, associada à sua crescente intervenção na economia e no território (sob o pretexto de sanar desigualdades sociais), que se acelerou o processo de ocupação da Amazônia com base na dominância absoluta da visão externa e privilégio das relações com o centro de poder nacional.

A fase inicial do planejamento regional (1930-1960) correspondeu à implantação do "Estado Novo" por Getúlio Vargas, e foi muito mais discursiva do que ativa. Foi à necessidade de unificar o mercado nacional, associada ao avanço da industrialização, que desencadeou a abertura da região. No governo de Juscelino Kubitchek, ações efetivas afetaram a região pela implantação das rodovias (1958) Belém-Brasília e Brasília-Acre. A partir daí, acentuou-se a migração que já se efetuava em direção a Amazônia, crescendo a população regional de um para cinco milhões entre 1950 e 1960 (BECKER, 2005).

A autora então pergunta: que lições podem ser extraídas desse processo? O privilégio atribuído aos grandes grupos e a violência da implantação acelerada da malha tecnopolítica, que tratou o espaço como isotrópico e homogêneo, com profundo desrespeito pelas diferenças sociais e ecológicas, tiveram efeitos extremamente perversos nas áreas onde foi implantada, destruindo, inclusive, gêneros de vida e saberes locais historicamente construídos. (BECKER, 2005) 
Dois processos têm como marco o ano de 1985: por um lado, certo esgotamento do nacional-desenvolvimentismo e da intervenção do Estado na economia e no território, pressionado pela redemocratização do país. Por outro lado, neste mesmo ano, um novo processo tem início com a criação do Conselho Nacional dos Seringueiros, simbolizando um movimento de resistência das populações à expropriação da terra. Somado à pressão ambientalista internacional e nacional, esse elemento resgatou o modelo endógeno sob várias formas e foi predominante na dinâmica regional entre nas décadas de 80 e 90 . (BECKER, 2005).

\begin{abstract}
O ano de 1996 é um novo marco. Neste ano, o projeto ambientalista propõe a formação de imensos corredores ecológicos para proteção ambiental. Mas no mesmo ano, o governo federal, após uma década de omissão, retoma o planejamento com o Programa Brasil em Ação, resgatando e fortalecendo o modelo exógeno e propondo a implantação de igualmente grandes corredores de desenvolvimento. Corredores de transporte e corredores de conservação implementam, respectivamente, os modelos exógeno e endógeno, orientados por políticas públicas paralelas e conflitantes. Políticas que expressam o embate de interesses econômicos e político-ideológicos diversos - em parcerias externas/domésticas - e influem na alteração do conteúdo do interesse nacional e da apropriação e uso do território. A coexistência conflitiva dos modelos endógeno e exógeno marca hoje a região (BECKER, 2005, p. 33).
\end{abstract}

Forças atuantes, em diferentes escalas geográficas, influem no novo contexto. Em nível global, tornam-se mais acentuadas as feições da globalização e da mundialização do mercado (CASTEL, 2004). Processo marcado pela interconexão não só da economia e das finanças, como das arenas políticas nacionais e internacionais, a redefinição do papel do Estado, os financiamentos descentralizados e a velocidade acelerada de transformação das atividades laborais.

Analisando as políticas públicas na história do Brasil, Becker (2005) conceitua-as como conjunto de interesses compartilhados pela sociedade nacional em suas interações com o mundo, baseado em valores fundamentais historicamente construídos, caracterizando-se por fim, como condicionantes geoeconômicos e geopolíticos. No Brasil, destacam-se como valores básicos, no âmbito discursivo, embora com inúmeras contradições no processo de implementação: a busca do desenvolvimento econômico, a autonomia, a paz, a coexistência com a diversidade cultural.

As políticas públicas para a Amazônia refletem o interesse nacional, com os citados valores históricos atualizados pela incorporação das demandas da cidadania; contudo, essa transição se expressa hoje em políticas públicas desarticuladas, que partindo de 
conceituações homogeneizantes e planificadoras, não compreendem a existência de muitas formas de cidadania que nascem e articulam-se com cada território. (LACERDA, 2016 b).

Na busca de analisar algumas consequências destas políticas públicas, vamos nos ater ao Plano Amazônia Sustentável de Aquicultura e Pesca, elaborado em 2009 com vigência até 2011, desenvolvido pelo Gabinete da República em parceria com Ministérios da Pesca, Agricultura, Integração e Desenvolvimento Social.

Tal projeto apresenta como objetivo geral Integrar programas, projetos e ações nos estados da região amazônica, voltados para a promoção do desenvolvimento sustentável do setor pesqueiro e aquícola, visando fortalecer as cadeias produtivas e melhorar a qualidade de vida de todos os envolvidos com a pesca e aquicultura (PASAP, 2009).

Levando em consideração, em seus objetivos específicos, as mudanças climáticas e a crise financeira internacional, as diretrizes do projeto indicam ser necessário trabalhar junto às populações locais ações que promovam a prevenção e a mitigação dos impactos causados às comunidades pesqueiras, apresentando o Estado como figura central nesta relação.

Percebe-se, portanto, a dinâmica planificadora e colonialista de um aparelho que apesar de construir discursos viáveis de desenvolvimento junto à população, apresenta-se como protetor patriarcal de um processo supostamente inevitável de desenvolvimento econômico que invariavelmente gera malefícios a serem sanados pelo Estado, o próprio interventor.

\footnotetext{
O objetivo da Política Territorial é a superação da pobreza e das desigualdades sociais junto às comunidades aquícolas e pesqueiras, pelo aprimoramento das capacidades de autogestão dos interesses coletivos, favorecendo a inserção do segmento nas cadeias produtivas do setor e a gestão sustentável dos recursos aquícolas e pesqueiros através da sua participação nos colegiados territoriais (PASAP, 2009, p. 5).
}

Contudo, o principal índice de embasamento do projeto referente à sua atuação na melhoria da qualidade de vida da população pesqueira, embasado no IDH da região, que segundo as informações do Plano em seu marco inicial apresentava-se em 0,757, após três anos de intervenção, manteve-se na faixa de 0.7 , não apresentando repercussões positivas.

Esses indícios nos levam a crer que, ou o discurso relatado acima foi operacionalizado de maneira equivocada, ou após o processo de intervenção estatal, as comunidades não conseguiram, por elas mesmas, dar continuidade autogestionada ao processo. 
Temos a tendência a concordar com Sanches (2010) ao apontar que as explicações usuais de falta de conhecimento, apoio técnico, autointeresse dos atores e desvios das políticas públicas não explicam o fracasso das iniciativas de desenvolvimento na Amazônia, mas sim a subordinação de peculiaridades locais a uma lógica macroeconômica que não garante o respeito aos micro processos locais, necessários para o êxito destas intervenções.

Segundo o autor, por trás desse cenário, encontram-se duas correntes que disputam espaço: uma primeira ligada à produção de subsistência, sem geração de excedentes e acumulação, baseando a estrutura social em vínculos de parentesco, elaborando mecanismos de redistribuição das sobras, garantindo certa estabilidade nos fluxos produtivos. Por outro lado, posiciona-se a corrente que busca gerar o maior excedente possível, incrementando a produtividade a partir de técnicas exógenas e mecanismos formais de remuneração proporcional.

Essa última corrente, analisada por Sanches (2010), representa as lógicas capitalistas convencionais que trazem para realidade amazônica uma racionalidade diferenciada, embasada na competição e na exploração contínua da terra, que traz como resultados a degradação ambiental, o individualismo e a inclusão social perversa. Instalado este quadro, "justifica-se" a intervenção e o controle estatal sobre a localidade onde, por fim, o discurso científico acaba por aliar-se com a política pública (por vezes partidária) e as práticas tradicionais de assistencialismo para reproduzirem desigualdades sociais.

Os mercados locais e regionais tendem a serem autossuficientes os mercados nacionais e internacionais exibem um comportamento de expansão e contração que esvazia os mercados locais em beneficio dos internacionais, empobrecendo as populações com vínculos locais, dada sua procura por integração. A maioria dos programas de desenvolvimento da Amazônia coloca a necessidade de ligar a região com os mercados nacionais. Sendo a justificativa inicial para a construção de infra-estrutura de energia e transporte que ligaria a região com o mundo. Somente que este plano beneficia aqueles com capacidade de integrar-se como os agricultores que produzem produtos com demanda externa, que possuem valor suficiente para pagar o transporte na exportação de grande escala. Isto obriga ao restante de produtores a adequar-se e iniciam praticas de uso que degradam e exaurem os recursos materiais e ambientais, os articulam desigualmente e levam a importação e ao consumo de produtos caros. (SANCHES, 2010, p. 23).

Aproximando-nos do território que desejamos analisar, os estudos de Alencar (2008), debruçam-se especificamente na região do Alto Solimões, realizando comparações a respeito das políticas públicas e da cultura de várzea característica daquele local. Nestas análises a condição da política pública aparece como extremamente precarizada, pois se 
desenvolve de maneira descolada da realidade dos moradores. Tal rede falta, através da estrutura pública mínima e obrigatória, em seus serviços mais básicos; a lógica familiar é quase sempre submetida à lógica mercantil e por fim, aponta a autora, faltam estruturas democráticas que realizem a mediação adequada entre população e órgãos de poder.

A falta de uma política eficiente no setor produtivo, por exemplo, afeta particularmente as famílias dos pequenos produtores rurais, em particular os moradores das áreas de várzea, que são responsáveis pelo abastecimento dos mercados urbanos com produtos agrícolas como a farinha, a banana etc. Apesar da importância da produção gerada por esse segmento social para a economia da região, não se observa por parte do poder pública a promoção de políticas públicas que atendam as demandas da população. (ALENCAR, 2008, p. 1).

Neste sentido, Alencar (2008) coloca que mesmo munidos de boas intenções, a maior parte das ações acaba por se caracterizar como assistencialista, citando Bolsa Família e Auxílio Floresta. Embora representem ganhos oriundos de lutas históricas, ao serem aplicados, as políticas podem apresentar distorções que acabam por reproduzir a lógica de submissão e dependência entre a população e a política pública.

\begin{abstract}
Apesar da falta de políticas de apoio a produção e de serviços sociais básicos, as mulheres avaliam o modo de vida dos moradores da várzea como bom, quando tomam como referencial a facilidade de obter alimentos e a capacidade de produção. Mas quando tomam como referencial a existência de uma infra-estrutura, o acesso a certos serviços públicos e as condições de trabalho e de produção, consideram a vida na várzea difícil, e o principal responsável é a falta de apoio do poder público municipal. Os raros investimentos na área social estão restritos a construção de escolas, ao fornecimento de energia elétrica com a doação de motores a diesel para a geração de eletricidade durante algumas horas no período noturno; à doação de televisores e de antenas parabólicas, também a doação de instrumentos de trabalho, como motores para cevar mandioca, fornos de torra massa para produzir farinha, moto-serra para corte de madeira, dentre outros (ALENCAR, 2008, p. 6).
\end{abstract}

O trecho referido acima nos oferece um retrato das contradições que caracterizam as tentativas de redução das desigualdades sociais nas suas relações com as políticas públicas.

Quando analisada na perspectiva das possibilidades de viver do que se faz, referindose às possibilidades que seu trabalho possui em produzir a vida cotidiana do trabalhador/a local e sua família, a avaliação das moradoras da várzea é positiva. Contudo, quando a matriz comparativa das entrevistadas se desloca para a parte que é cabível ao poder público, a análise torna-se extremamente negativa, sendo grande parte das ações voltadas a um processo adaptativo destas comunidades ao contexto mercantil e às tecnologias exógenas. 
As práticas assistencialistas subtraem das comunidades seu poder de autogestão, provocando passividade e dependência que acabam por gerar um ciclo que se retroalimenta:

Se o prefeito ajudasse, a gente podia mudar, mas só a gente mesmo, como que a gente vai mudar? Sem a ajuda do prefeito como é que vai mudar? Se pelo menos uma vez por ano ele viesse olhar a gente ao menos. Eu pelo menos não conheço o prefeito nem em papel, só sei que eu voto, mas não conheço nada (Antônia, Novo Progresso) (ALENCAR, 2008, p. 8).

Mesmo apontando que ainda é necessária a realização de pesquisas mais aprofundadas sobre os efeitos dos programas de transferência de renda nesta região, é possível afirmar, como conclui a Alencar (2008), que se mostra o imperativo de reelaborar as intervenções públicas dentro da região do Alto Solimões e na Amazônia em geral. Isso porque, no que cabe às populações rurais, corre-se o risco de eternamente reproduzir o ciclo de produção das desigualdades, devendo, contra isso, ser a participação comunitária ativa em todas as etapas das políticas o elemento chave para a elaboração de novas formas de intervenção.

Torres (2007), atentando para essas lógicas peculiares de organização cultural e laboral no contexto do Alto Solimões, ressalta:

\begin{abstract}
Nas sociedades indígenas da Amazônia, a família e as relações que dela resultam constituem-se no elemento organizador da economia. A divisão sexual do trabalho é o suposto da produção e tem nas atividades femininas o ponto basilar da organização do trabalho. Na etnia Ticuna da Amazônia brasileira (umas das etnias mais numerosas ainda existentes em nosso país, assim como na Amazônia colombiana) a mulher é preparada para realizar o trabalho de artesã. A menina quando atinge a menarca é submetida a um noviciado moçangol. Ela fica mais de 30 dias isolada num determinado local sem ver o sol. Somente a mãe ou a irmã mais velha têm a autorização do pajé ou xamã para entrar no local, dar-lhe alimento e auxiliá-la na higiene corporal. A menina entra em reclusão para aperfeiçoar as prendas domésticas e aprender a fazer os utensílios que irá utilizar na sua casa após o casamento, depois de passar pelo ritual da moça-nova. (p. 2).
\end{abstract}

A autora relata que apesar dessas práticas (junto a tantas outras) serem de extrema importância no modo que essas populações administram suas vidas diárias, não são incorporadas às estratégias de políticas públicas, homogeneizando-se as diversas etnias indígenas sob um universo artificialmente unificado, impondo-lhes lógicas alheias às suas, provocando, em última análise, um abismo entre intervenções públicas e realidades sociais.

Sendo assim, as práticas culturais ignoradas impedem uma efetividade maior das políticas para a região. Completa a autora: "na sociedade ticuna, toda a lógica subjacente ao 
sistema que informa as ações e o comportamento indígena em suas relações sociais, particularmente no que se refere àquelas entre homens e mulheres, reside no modo como os sujeitos percebem e organizam o seu universo cultural. " (TORRES, 2007, p. 7).

Parece-nos que a cultura dessas comunidades na esfera laboral engendra relações através de uma lógica coletiva, tornando-se praticamente incompatível com as premissas das políticas de Estado. Essas, quando muito, aderem ao discurso cooperativo, subsidiado por interesses de crescimento mercantil que não têm ligação com as reais motivações das populações indígenas e ribeirinhas. Para tais populações, suas próprias ações parecem partir de uma micropolítica embasada em uma cosmovisão partilhada, ações de solidariedade e compartilhamento dos recursos existentes. (LACERDA, 2012).

Outro exemplo de política pública que nasce sob o pretexto de combater as desigualdades sociais e ganha ênfase nos territórios amazônicos é o Programa de Aquisição de Alimentos (PAA) e o Plano Nacional de Promoção das Cadeias de Produtos da Sociobiodiversidade (PNPSB), ligados à Secretaria Nacional de Economia Solidária (SENAES). Também estão interligados a outros sete Ministérios, representando as ações efetivas do Programa Fome Zero e Programa Nacional de Agricultura Familiar (PRONAF).

Sob o financiamento do governo brasileiro e do Banco Internacional para Recomposição do Desenvolvimento (BIRD), o que se demonstrou, com a criação dos Eixos de Integração e Desenvolvimento e a Política de Integração de Transportes foi o interesse de construir uma malha mercantil de fluxo integrativo entre sudeste, nordeste e norte, sob o "novo" discurso da sustentabilidade e do desenvolvimento local.

Ao serem selecionadas as cidades participantes destes projetos pelo critério de malha multidimensional de transportes e hierarquia funcional (referente à logística e infraestrutura disponível em cada local) automaticamente deixou-se de fora a grande maioria das realidades amazônicas que tradicionalmente não dispõem destes requisitos.

Sobre este caso, Simoni (2010, p. 54) afirma:

Devido sua importância, a rodovia BR- 174 foi atendida pelo PAC (Programa de Aceleração Econômica, criado no primeiro mandato do Governo de Luís Inácio da Silva) como obra prioritária de desenvolvimento econômico na região. A escolha não foi inocente, mas se reveste de grande estratégia geopolítica em razão de atender a certas demandas econômicas do grande capital instalado na área de livre comércio de Manaus, sendo inclusive uma porta de entrada para a capital da Venezuela. Com essas características, trata-se de uma nova área de regionalização que tende a se concentrar nesse eixo com outras iniciativas, tais como: a construção e a ligação da Hidrelétrica de Guri, para abastecer Boa Vista e outras cidades do Estado de Roraima. 
Becker (2005) ressalta que, no âmbito das lutas contra as desigualdades sociais na Amazônia, existem dois caminhos possíveis para não incorrermos nos erros já criticados: Ou partimos para a produção de modelos endógenos de desenvolvimento ou devemos realizar uma apropriação local das intervenções públicas, sob a égide do protagonismo comunitário, para redimensioná-las ao longo dos percursos, adaptando-as às necessidades de cada lugar. Os dois caminhos levariam ao mesmo lugar: adequar políticas públicas as realidades locais, quando não fosse possível criá-las a partir daí mesmo.

Exemplificando este último elemento de apropriação, a autora evoca o caso do Plano para Proteção das Florestas Tropicais Brasileiras (PPG-7).

Tal Programa, negociado em Genebra em 1991 e colocado em prática em 1994, é financiado pela União Europeia, Canadá, Japão e Estados Unidos, administrado pelo Banco Mundial com investimentos previstos em 250 milhões de dólares. É o maior programa ambiental implementado em um só país. Além de atribuir às ONGs papel importante na efetivação de suas atividades, busca, em seus objetivos, proteger os recursos genéticos e conter o desmatamento, motivado, implicitamente, a projetar reservas de espaço e mercado para estudos bioquímicos e desenvolvimento de novas tecnologias de combustível.

Mesmo com essas implícitas motivações ligadas à exploração mercantil, Becker (2005) afirma que foi o PP-G7 que se transformou no grande indutor dos projetos endógenos, através de uma estratégia descentralizada que envolve as principais reivindicações sociais, onde os resultados destacam as áreas protegidas e os projetos comunitários alternativos que transformaram a Amazônia em verdadeira fronteira experimental de um novo padrão de desenvolvimento.

As áreas protegidas localizam-se na floresta. Referem-se, por um lado, à demarcação de Terras Indígenas, uma conquista dos direitos coletivos das comunidades indígenas, que começou a ser aceita pelo governo em 1991 e tem resultado na demarcação de seus territórios e fortalecido seu papel como atores políticos no cenário regional. Entre 1995 e 1998, o governo reconheceu 58 Reservas Indígenas, correspondendo a 26 milhões de ha, e demarcou 115 , equivalendo a $311.000 \mathrm{~km} 2$, de modo que $63 \%$ das terras indígenas estão hoje demarcadas, representando $78 \%$ da área total de reservas nacionais. Por outro lado, as áreas protegidas se referem às Unidades de Conservação (UCs), de vários tipos, que se multiplicaram na Amazônia a partir de meados de 1980, mas cujo gerenciamento se constitui no ponto nevrálgico, dadas sua extensão e falta de pessoal. Hoje, cerca de $22 \%$ de território amazônico e mais de $6 \%$ são ocupados, respectivamente, por terras indígenas e unidades de conservação. (BECKER, 2005,p. 18). 
Na busca de reflexão crítica na constituição das práticas endógenas, fica a lição de que devemos distinguir com clareza as diferenças entre planos, projetos, mapas e a realidade social.

Além disso, pensar as redes de comunicação e transporte, aproximadas das matrizes de produção e locomoção locais, no sentido de causar menor impacto possível nos necessários processos de integração, mostra-se fundamental. Não existe ainda, de forma sólida, a criação de espaços sistemáticos de interlocução entre poder público e comunidades (in lócus) no sentido de garantir o diálogo e o espaço de negociação das demandas populares frente às lógicas e objetivos pré-estipulados das políticas públicas. Por fim, percebe-se que a noção de território que subjaz essas intervenções é meramente geográfica, e não parecem incluir a concepção trazida por Milton Santos:

\begin{abstract}
O território tem que ser entendido como o território usado, não o território em si. O território usado é o chão mais a identidade. A identidade é o sentimento de pertencer àquilo que nos pertence. O território é o fundamento do trabalho, o lugar da residência, das trocas materiais e espirituais e do exercício da vida. O território em si não é uma categoria de análise em disciplinas históricas, como a Geografia. É o território usado que é uma categoria de análise. (Santos, 1999, p. 8)
\end{abstract}

Inclusive, sobre a Questão Amazônica a luta que se perpetua ao longo das décadas é justamente a do chão mais a identidade, a luta por território e demarcação das terras. Albó (2015) demonstra com clareza que, mesmo entre os anos 2000 e 2010 onde houve uma ascensão majoritária de governos de esquerda na América Latina, os discursos eleitorais corroeram-se frente a futura governabilidade econômica dos estados nacionais, promovendo por vezes inclusive, invasão mais sagaz do que em tempos de outrora.

Assim assinala o autor refletindo o caso do Peru, ou mesmo da Bolívia e do Equador, que despontam com reformas constitucionais de caráter inclusivo e multiétnico dentro de suas concepções de nação. Assim assinalamos nós, no Brasil, com a própria evolução da Proposta de Emenda Constitucional 215, que busca transferir do poder Executivo para o Poder legislativo a prerrogativa de demarcação das terras indígenas, quilombolas e unidades de conservação, em um pais onde $48,7 \%$ dos Deputados federais e $19,7 \%$ do Senadores possuem algum tipo de vinculação com o agronegócio, formando a chamada Bancada Ruralista. (MARTINS, 2015). 
Neder (2010), através de análise de cunho jurídico dos processos estatais, na busca de compreender a relação entre o Estado e a sociedade civil, acaba, ao final de sua reflexão, por chegar a termo similar ao de Becker (2005) analisando a Amazônia.

\begin{abstract}
Como pode uma sociedade sob um Estado republicano centralizado e nacional emergente a partir do século $X X$, reconhecer a si própria, dada a existência de sujeitos diferentes tão excluídos? Daí ser um pensamento político institucional, jurídico e sociológico que se debate entre romper o dever de proteger os princípios comunitários das corporações e privilégios de ofício - ainda presentes na maioria das nossas atividades econômicas herdadas do antigo regime do Estado desenvolvimentista autoritárias das segundas metades do século XX e as dificuldades em definir uma nova economia política cujo pleno desenvolvimento depende da ação política ativa de uma parte da sociedade civil e do campo estatal. (NEDER, 2010 p. 3).
\end{abstract}

Para o autor, as ações do Estado geralmente colocam-se em sentido reparador dos interesses gerais, mas enfraquece sua própria legitimidade por não dar conta de tamanha multiplicidade e, daí, entra em crise de regime.

\begin{abstract}
Quando o poder público não é o garante jurídico e institucional, a pretensão de soberania do estado é destituída de base social, já que fracassam tanto o que Max Weber chamou de domínio organizado do território, quanto à relação das pessoas no plano subjetivo ou interno de sua privacidade, inviabilizando o mínimo de sociabilidade política que supere o isolamento, como nos lembra $\mathrm{H}$. Arendt. Aqui -- como em outras sociedades civis restritas herdeiras do Estado colonial nas Américas -- não se trata hoje apenas do problema da inclusão econômica de vastas camadas sociais enquanto consumidores. (NEDER, 2010, p. 12).
\end{abstract}

Porém, essas manifestações contemporâneas ligadas às políticas públicas na Amazônia possuem origens mais antigas. O próprio Wanderley (2004), além de explicitar a origem da questão social amazônica nascente concomitantemente com o início do contato do homem europeu com o homem nativo das Américas, comenta os processos de colonização e manutenção da relação de desigualdade ao longo dos tempos. A princípio, refere o autor, podemos perceber duas concepções de manejo com o índio: uma socioeconômica e outra ético-jurídica.

Essas duas concepções, respectivamente, fazem jus a duas Leis: a de Burgos (1512) que representava a privatização do índio por parte dos donos das terras e a Nuevas (1542) que representava a estatização do índio, pertencendo à Coroa. Esta última incentivando posteriormente a abertura dos processos de evangelização.

Matanças, tomadas de terras, massacres, atrasos nas demarcações, conflitos fundiários, pressões de políticos e grupos interessados nas terras pela revisão dos 
dispositivos institucionais constituem fatos concretos dessa história interminável. A resistência dos índios e a luta por sua identidade, memória, autonomia, convivência pluralista, etc., também persistem adquirindo novas feições tais como, manifestações públicas, filiações a partidos políticos, associações, invasões de terras, e ultimamente no Brasil, invasões de agencias públicas, tomadas de reféns, acampamentos nas cidades, além de conquista de aliados em países de outros continentes que apoiam sua causa, e outras que constituem essa saga secular. (WANDERLEY, 2004, p. 80).

Afirmamos, assim, que a Questão Social Amazônica tem um longo histórico, tendo-se iniciado há pelo menos 514 anos e continuando atual em seus desdobramentos, tomando diferentes roupagens ao longo do tempo. O que permeia toda essa história desde sua gênese, é a manutenção das desigualdades sociais que até hoje vigoram. Portanto, uma questão antiga, multifacetada em seus aspectos culturais, políticos, religiosos e econômicos, pautada pela escravidão, privatização, estatização e exploração sobre um povo e seu território.

Desse modo, podemos concluir que a questão social na região amazônica não é nova em matéria, porém reveste-se de transformações sistemáticas em sua forma, que varia de acordo com cada época e suas tendências políticas e econômicas. A partir do exposto ao longo do texto, podemos afirmar que tentar compreender tal questão sob uma perspectiva eurocentrista relacionada à fratura de uma sociedade salarial e o falecimento de um Estado de Bem-Estar Social seria um equívoco analítico.

Na questão social amazônica encontram-se elementos de mestiçagem, hibridação, relações de poder e formas de viver típicos da região. Define-se, portanto, como uma questão de origens próprias, origens no colonialismo/colonialidade e posteriormente no assistencialismo, movida por interesses secundários de integração comercial de suas riquezas naturais e ocupação populacional de seus espaços de fronteira. Uma questão econômica, social e também política, que deflagra a crise ontológica de uma democracia que se pretende representativa e de uma política pública cega e surda ás demandas da população. Uma questão epistemológica, que nos convida a pensar, enquanto nação, qual lugar ocuparam/ocupam/ocuparão os povos tradicionais e a selva amazônica? Portanto, não é nova e tampouco homogênese a questão amazônica.

\section{Referências}

ALBÓ, Xavier. Os Grandes desafios dos indígenas nos países andinos: seus direitos sobre os recursos naturais. Cadernos IHU ideias. São Leopoldo-RS, v. 13, ano 13, n. 225, 2015. 
ALENCAR, Edna Ferreira. Gênero, políticas públicas e sustentabilidade social na várzea do Alto Solimões, AM. In: SIMPÓSIO TEMÁTICO INTERSECÇÕES ENTRE GÊNERO E SOCIODIVERSIDADE AMAZÔNICA. Florianópolis: UFSC, 2008.

BECKER, Bertha. A Amazônia nos Cenários para o Planejamento Ambiental. In: Atlas: Os Ecossistemas Brasileiros e os Principais Macrovetores de desenvolvimento. Brasília: MMA. 1995. p. 135-159.

BRASIL. Ministério da Pesca e da Agricultura. Plano Amazônia Sustentável de Aquicultura e Pesca- PASEP, 2009. Disponível em: www.pasap.mpa.gov.br. Acesso em: 26 mai. 2012.

CASTEL, Robert. As transformações da questão social. In: BELFIORE-WANDERLEY, Mariângela; BÓGUS, Lúcia; YAZBEK, Maria Carmelita (Org.). Desigualdade e a questão social. São Paulo: EDUC, 1997. p. 235-264.

COUTINHO, Marcelo. Movimentos de Mudança Política na América do Sul Contemporânea. Rev. Sociol. Polít. Curitiba, v. 27, p. 107-123, nov. 2006.

DEDECCA, Claudio Salvatori; BALTAR, Paulo Eduardo de Andrade. Mercado de trabalho e informalidade nos anos 9o. Estudos Econômicos, Inst. Pesq. Econ. São Paulo, v.27, p. 65-84, nov., 1997.

GALEANO, Eduardo. As veias abertas da América Latina. 12. Edição. São Paulo: L\&PM, 1999. 392 p.

GORZ, André. Adeus ao proletariado - para além do socialismo. Rio de Janeiro: Forense Universitária, 1987. In: PASTORINI, Alejandra. A categoria A questão Social em debate. São Paulo: Cortez, 2004.

IBGE - INSTITUTO BRASILEIRO DE GEOGRAFIA ESTATÍSTICA. Reflexões sobre Censo. São Paulo, 2010. Disponível em: www.ibge.gov.br Acesso em: 25 jun. 2012.

LACERDA, Luiz Felipe. A realidade indígena e a busca por reconhecimento. In: LIBÓRIO, Ana. Propostas \& Contribuições: Educação, Saúde e Política. Manaus: B\&K Editora, 2012, p. 136- 164.

O Educador Indígena: Caminhos e desafios. In: LACERDA, L. F; RODRIGUES, D. et al. Vivencias Pedagógicas: relatos da trajetória de vida de professores indígenas no Alto Solimões AM. Manaus: UEA Editora, 2016a, p. 101-131.

Por uma Sociologia das Emergências: Perspectivas de Emancipação nos territórios de ausências amazônicas. 2016. [?]f. Tese (Doutorado em Ciências Sociais) - Programa de Pósgraduação em Ciências Sociais, Universidade do Vale do Rio dos Sinos, UNISINOS, São LeopoldoRS, 2016b.

LIMA, Wendell Teles de; SILVA, latiçara Oliveira da; SOUSA, Lucileyde Feitosa. Breve retrospectiva das estratégias geopolíticas de incorporação territorial da Amazônia brasileira. Raega - O Espaço Geográfico em Análise. [S.I.], v. 24, mar. 2012. Disponível em: <http://ojs.c3sl.ufpr.br/ojs2/index.php/raega/article/view/26206> Acesso em: 31 out. 2012.

MARTINS, R. Kátia Abreu, a ministra que desmata a razão. Revista Carta Capital. São Paulo, 2015. Disponivel em: http://www.cartacapital.com.br/revista/832/a-ministra-desmata-a-razao-66o1.html. Acesso em: 26 set. 2017. 
MÉDA, D. Lê Travail: une valuer em voie de disparition. Paris: Auto Aubier, 1995, 215 p.

MELLO, Thiago. Mormaço na Floresta. São Paulo: Circulo do Livro, 1987, 162 p.

MOTA, Ana Elizabete. Cultura da crise e seguridade social. Um estudo sobre as tendências da previdência e da assistência social brasileira nos anos 8o e 9o. São Paulo: Cortez, 1995. 245 p.

NARDI, Henrique. Ética, trabalho e subjetividade. Porto Alegre: UFRGS, 2006. 224 p.

NEDER, Ricardo Toledo. Estado e sociedade civil diante da nova economia solidária no Brasil (qual governança e controlabilidade?). Revista do Tribunal de Contas do Município do Rio de Janeiro. Rio de Janeiro, v. 1, p. 15-33, 2010.

PASTORINI, Alejandra. A categoria A questão Social em debate. São Paulo: Cortez, 2004. 128 p.

QUIJANO, Aníbal. Colonialidade do poder, eurocentrismo e América Latina. In: LANDER, Edgardo (Org). A colonialidade do saber: eurocentrismo e ciências sociais. Perspectivas latino-americanas. Buenos Aires: CLACSO, 2005. p. 227-278.( Colección Sur Sur).

RIFKIN, Jeremy. El fin del trabajo: nuevas tecnologías contra puestos de trabajo y el nacimiento de una nueva era. Buenos Aires: Paidós, 1997. 399 p.

SANCHES, Camilo Torres. O pensamento disciplinar e o desenvolvimento: uma analise das políticas públicas ambientais para o uso da terra na amazonia brasileira. In: VIII CONGRESSO LATINOAMERICANO DE SOCIOLOGIA RURAL. Anais..., 2010. Porto de Galinhas: Universidade Federal Rural de Pernambuco (UFRPE), 2010.

SANTOS, Milton. O Dinheiro e o Território. GEOgraphia, América do Norte, 1, set. 2009. Disponível em: http://www.uff.br/geographia/ojs/index.php/geographia/article/view/2/2. Acesso em: 31 out. 2012.

SIMONI, Jane. Economia solidária e políticas públicas a revitalização do extrativismo: práticas de economia solidária e sustentabilidade. Revista Mercado de trabalho - IPEA., v. 42, p. 49-54, fev. 2010.

TORRES, Iraildes Caldas. A visibilidade do trabalho das mulheres ticunas da Amazônia. Revista Estudos Feministas. Florianópolis, v. 15, n. 2, 240, p. 469-475, maio-agosto/2007.

WANDERLEY, Luiz E. W. A questão social no contexto da globalização: o caso latino-americano e o caribenho. In: BÓGUS, L.; YAZBEK, M.C.; WANDERLEY, M.B. (Org.). Desigualdade e a questão social. São Paulo: Educ, 2004. p. 51-161.

\section{Abstract}

This article deals with the relationship between the concept of Social Issue developed by Robert Castel, the specifics of Latin America and especially in the Amazon region of Alto Solimões, as well as the public policies designed and implemented to take account of the problems experienced there. It is concluded that, on the issue of social question in the Amazonian context studied, there are elements such as miscegenation, hybridisation, power relations and typical ways of living. Sets itself, therefore, as a multifaceted issue, with its own configuration and cannot be explained on the basis of an overall analysis. With origins in colonialism and later in 
paternalism, was and is moved by secondary interests of commercial integration of its natural wealth and occupation of their of border spaces.

Keywords: Social issue. Amazonian context. Public policies. 